\title{
Endurance factors improve hippocampal neurogenesis and spatial memory in mice
}

\author{
Tali Kobilo, Chunyan Yuan, and Henriette van Praag ${ }^{1}$
}

Neuroplasticity and Behavior Unit, Laboratory of Neurosciences, Intramural Research Program, National Institute on Aging (NIA), Baltimore, Maryland 21224, USA

\begin{abstract}
Physical activity improves learning and hippocampal neurogenesis. It is unknown whether compounds that increase endurance in muscle also enhance cognition. We investigated the effects of endurance factors, peroxisome proliferator-activated receptor $\delta$ agonist GW501516 and AICAR, activator of AMP-activated protein kinase on memory and neurogenesis. Mice were injected with GW for $7 \mathrm{~d}$ or AICAR for 7 or $14 \mathrm{~d}$. Two weeks thereafter mice were tested in the Morris water maze. AICAR (7 d) and GW improved spatial memory. Moreover, AICAR significantly, and GW modestly, elevated dentate gyrus neurogenesis. Thus, pharmacological activation of skeletal muscle may mediate cognitive effects.
\end{abstract}

Physical activity has many benefits for brain function ranging from memory to mood (Hillman et al. 2008). There is a strong positive correlation between running and performance in hippocampus-dependent spatial memory tasks (van Praag 2008). Research into mechanisms underlying effects of running on the brain has mainly focused on changes in neurotransmitters, neurotrophins, spine density, and hippocampal neurogenesis (Cotman et al. 2007; Gomez-Pinilla et al. 2008; Hillman et al. 2008; van Praag 2008). Conversely, the peripheral triggers of the cellular and molecular cascades in the brain that lead to improved cognition have remained unclear. It has been suggested that serum insulin-like growth factor-1 (IGF) may play a role as the peripheral blockade abolished the running-induced enhancement of hippocampal neurogenesis (Trejo et al. 2001). Similar observations were made following systemic blockade of vascular endothelial growth factor (VEGF) (Fabel et al. 2003). However, the possibility that skeletal muscle activation as a result of exercise or pharmacological agents underlies cognitive effects of aerobic activity has not been explored.

Recently, transcriptional factors regulating muscle fiber contractile and metabolic genes have been identified (Wang et al. 2004). The peroxisome proliferator activated receptor $\delta$ (PPAR $\delta$ ) is a transcription factor that regulates fast-twitch muscle fiber contraction and metabolism. Overexpression of this factor increased oxidative muscle fiber number. In addition, administration of the selective agonist GW501516 increased exercise stamina when combined with training (Narkar et al. 2008). PPAR $\delta$ is controlled by the AMP-activated protein kinase (AMPK), a master metabolic regulator important for glucose homeostasis, appetite, and exercise physiology (Hardie 2004). Treatment with AMPK agonist AICAR enhanced running endurance by $45 \%$ in sedentary mice (Narkar et al. 2008). It has not been determined whether the effects of these compounds extend from the periphery to brain function, and may influence hippocampal neurogenesis and spatial memory. Here we show that systemic pretreatment with AICAR, and more modestly, GW501516, 2 wk prior to behavioral testing enhances spatial learning and hippocampal neurogenesis.

In the present study, female C57BL/6J mice (Jackson Laboratory, Bar Harbor, ME) 2-mo-old, were housed under standard conditions, three mice per cage, with food and water ad libitum. Mice

${ }^{1}$ Corresponding author.

E-mail vanpraagh@mail.nih.gov.

Article is online at http://www.learnmem.org/cgi/doi/10.1101//m.2001611. were injected intraperitoneally (i.p.) with GW501516 (GW, 5 mg/ $\mathrm{kg} /$ day; for $7 \mathrm{~d}$; Enzo Life Sciences) dissolved in oil vehicle (Premium MCT Gold, Ultimate Nutrition Inc.) or an equal volume of oil; or 5-Aminoimidazole-4-carboxamide-1- $\beta$-D-ribofuranoside (AICAR, Toronto Research Chemicals Inc.) dissolved in saline, $500 \mathrm{mg} / \mathrm{kg} /$ day or saline for 7 (ACR7) or $14 \mathrm{~d}$ (ACR14) (Table 1). The mice concurrently received bromodeoxyuridine (BrdU) injections $(50 \mathrm{mg} / \mathrm{kg}$; on days 1-7 [ACR7], days $1,3,5,7,9,11,13$ [ACR14], and days 1, 3, 5, 7 [GW] of treatment; Table 1). Mice were tested in the water maze starting $2 \mathrm{wk}$ after the last drug injection. After completion of water-maze testing, animals treated with GW and ACR7 were evaluated in the open field and accelerating rotarod. For histological analysis of ACR7 a separate group of mice that had not been behaviorally tested was evaluated for BrdU labeling. These mice were sacrificed either $1 \mathrm{~d}$ after the end of the injections to evaluate new cell proliferation, or 1 mo after to evaluate cell survival. All animal procedures were approved by the National Institute of Health Animal Care and Use Committee, protocol 396-LNS-2011.

Mice were trained in the Morris water maze (Morris et al. 1982) to find a platform hidden $5 \mathrm{~mm}$ below the surface of a pool (1.40-m diameter) filled with water made opaque with white nontoxic paint. Starting points were changed daily for each trial. A trial lasted either until the mouse had found the platform or for a maximum of $60 \mathrm{sec}$. Mice rested on the platform for $10 \mathrm{sec}$ after each trial. ACR7 mice were trained with two trials per day over 11 $\mathrm{d}$ and, subsequently, to a new platform location with four trials per day over $5 \mathrm{~d}$. ACR14 and GW mice were trained with four trials per day over 7 and $8 \mathrm{~d}$, respectively. Upon completion of training, the platform was removed for 60 -sec probe trials. Platform latency was recorded (Anymaze, Stoelting Co.).

In the open field test, mice were placed in the center of the open field arena and allowed to move freely for $30 \mathrm{~min}$ while being tracked by an automated tracking system (Activity Monitor Version 4, MED Associates). Mice were also tested on an accelerating rotarod (Med-Associates), 2.5-25 RPM in $300 \mathrm{sec}$. The latency to the first fall was recorded three consecutive times.

For histological analysis, animals were deeply anesthetized with isofluorane and perfused transcardially with $0.9 \% \mathrm{NaCl}$ solution, followed by $4 \%$ (wt/vol) paraformaldehyde (PFA) in 0.1 $\mathrm{M}$ phosphate buffer ( $\mathrm{pH} 7.4$ ). Brains were postfixed in $4 \%$ PFA for $3 \mathrm{~d}$, followed by equilibration in 30\% (wt/vol) sucrose. Tissue was sectioned coronally $(40 \mu \mathrm{m})$ on a freezing microtome (Thermo- Fisher) and stored at $-20^{\circ} \mathrm{C}$ in cryoprotectant solution. 
Table 1. Compound treatment and neurogenesis

\begin{tabular}{lllcc}
\hline Group & $\mathbf{N}$ & \multicolumn{1}{c}{$\begin{array}{c}\text { BrdU } \\
\text { injections }\end{array}$} & $\begin{array}{c}\text { BrdU }^{+} \\
\text {cell NR }\end{array}$ & $\begin{array}{c}\text { Percent } \\
\text { BrdU/NeuN }\end{array}$ \\
\hline SAL7 & 7 & 7, daily & $1879 \pm 126$ & $80.37 \pm 2.88 \%$ \\
ACR7 & 10 & 7, daily & $2595 \pm 121^{* *}$ & $89.62 \pm 1.88 \% *$ \\
SAL14 & 8 & 7, every other day & $1350 \pm 87$ & n.d \\
ACR14 & 7 & 7, every other day & $1272 \pm 82$ & n.d. \\
VEH & 10 & 4, every other day & $562 \pm 70$ & $85 \% \pm 2.5 \%$ \\
GW & 8 & 4, every other day & $746 \pm 72^{\#}$ & $90 \% \pm 2.2 \%$ \\
\hline
\end{tabular}

Female C57BI/6 mice were injected with saline $(\mathrm{SAL})$ or AICAR $(500 \mathrm{mg} / \mathrm{kg})$ daily for 7 (ACR7) or 14 d (ACR14), and with GW501516 (5 mg/kg) or vehicle (VEH) daily for $7 \mathrm{~d}$. BrdU $(50 \mathrm{mg} / \mathrm{kg})$ was injected concurrently. One month after the last injection, $\mathrm{BrdU}^{+}$cell number and differentiation (BrdU/ NeuN) were quantified. New cell survival $(* * P<0.0012)$ and neurogenesis $\left({ }^{*} P<0.018\right)$ were significantly increased in ACR7 as compared with SAL7 controls. In the GW-treated mice a trend toward increased cell survival ${ }^{\#} P=$ 0.08 ) as compared with VEH was observed.

For the GW experiment a 1:6 series of sections was used for immunostaining, using double-cortin (DCX) anti-goat, 1:500 (Santa Cruz Biotechnology) in combination with the secondary antibody donkey anti-goat IgG (Jackson) conjugated with CY5 (1:250), or the secondary antibody donkey anti-goat biotin (1:250, Jackson), followed by $\mathrm{ABC}$ reagent (Vector laboratories) and peroxidase detection for $5 \mathrm{~min}$ using diaminobenzedine (DAB) as chromogen $\left(0.25 \mathrm{mg} / \mathrm{mL} \mathrm{DAB}, 0.01 \% \mathrm{H}_{2} \mathrm{O}_{2}\right)$. DCXDAB-labeled cells were counted in the dentate gyrus in four equidistant sections ( $240 \mu \mathrm{m}$ apart), from rostral to caudal, through a 40x objective (Olympus BX51).

Immunohistochemistry for BrdU and immunofluorescent double-labeling for BrdU and the Neuronal marker NeuN were performed on a one-in-six series of equidistant $(240 \mu \mathrm{m}$ between sections) free-floating $40-\mu \mathrm{m}$ coronal sections. The antibodies used were rat anti-BrdU (1:100, Accurate; Harlan Sera-Lab) and mouse anti-NeuN (1:100, Millipore). The fluorescent secondary antibodies used were donkey anti-mouse Cy3 (Jackson Immuno Research) and donkey anti-rat Alexa-Fluor 488 (Invitrogen) at a concentration of $4 \mu \mathrm{g} / \mathrm{mL}$. To determine the number of surviving BrdU-labeled cells in the GW, ACR7, and ACR14 experiments, staining for BrdU with the peroxidase method was used as described (Creer et al. 2010) and the total number of BrdUpositive cells was counted in a 1:6 series of equidistant $(240 \mu \mathrm{m}$ apart) rostral-caudal sections. For cell proliferation, BrdU-labeled cells were quantified using the fractionator software; the area of the dentate gyrus was traced, and a counting frame $(0.35 \times 0.35$ $\mu \mathrm{m}$ ) was used to estimate the number of new cells using a $20 \mathrm{X}$ objective (StereoInvestigator system, MicroBrightfield Inc, VT; Olympus BX51).

Sections from GW and ACR7-treated animals surviving $4 \mathrm{wk}$ after the last injection of BrdU were double-labeled for BrdU and NeuN as described above, analyzed by confocal microscopy (Olympus IX81 spinning disk confocal), and were quantified using imaging software (Slidebook; Intelligent Imaging Innovations, Inc.). Fifty BrdU-positive cells per animal were analyzed for coexpression of BrdU and NeuN for neuronal phenotype. Ratios of BrdU-positive cells colabeling with NeuN were determined.

ANOVA (with repeated measures over days) was applied to the water-maze training data and open-field distance traveled, and ANOVA (factorial) was used for the probe trial analysis. Histological data was analyzed using Student's t-tests.

As illustrated in Figure 1, memory function was enhanced following administration of AMPK agonist AICAR $(500 \mathrm{mg} / \mathrm{kg})$ for 1 wk (ACR7), but not 2 wk (ACR14). The ACR7 mice (saline, $n=12$; drug, $n=11$ ) were trained in the Morris water maze (Morris et al. 1982) with two trials per day over $11 \mathrm{~d}$, a challenging training paradigm used previously in exercise and learning studies (van Praag et al. 1999). Latency did not differ between the groups $\left(F_{(1,21)}=0.60, P>0.45\right.$; Fig. 1A). However, ACR7 mice performed significantly better than saline-treated mice (SAL7) in the probe trials. Four hours after testing on day 8 , ACR 7 mice spent more time in the target quadrant than SAL7 mice $\left(t_{(21)}=2.17, P<\right.$ 0.05 ; Fig. 1B). Moreover, at $4 \mathrm{~h}$ after the last training trial on day 11, ACR7 mice spent more time in the target quadrant as compared with all other quadrants, $\left(F_{(3,40)}=4.22, P<0.01\right.$; one-way ANOVA over quadrants), whereas SAL7 mice did not, $P>0.05$ (Fig. 1C). To further assess enhancement of memory function, the same groups of mice were trained with four trials per day over $5 \mathrm{~d}$ to a new platform location. Latency did not differ between groups $\left(F_{(1,21)}=1.18, P>0.32\right)$ but task retention was enhanced, as evidenced by significantly more time spent in the target quadrant as compared with all other quadrants in only the ACR7 mice at $4 \mathrm{~h}(P<0.006)$ and $24 \mathrm{~h}(P<0.04)$ after the last acquisition session on day 5 (Fig. 1D,E). Since the retention of the task was more apparent upon training the mice with four trials per day, we continued using this paradigm in the next experiments (ACR14 and GW). Open-field total distance (SAL7, $3541 \pm 199 \mathrm{~cm}$; ACR7, $\left.3010 \pm 762 \mathrm{~cm} ;\left[F_{(1,15)}=2.61, P>0.13\right]\right)$ and the average latency to first fall from the rotarod (SAL7, $175.5 \pm 35.7 \mathrm{sec} ;$ ACR7, $220.3 \pm 23.2 \mathrm{sec} ;\left[F_{(1,15)}=1.15, P>\right.$ 0.30]) were unchanged.

Interestingly, longer administration of the compound for 2 wk (ACR14) prior to testing did not benefit learning (SAL14, $n=8$; ACR14, $n=7$ ). Indeed, even though the total number of training trials (28 trials) for ACR14 was greater than in the initial ACR7 experiment (22 trials), the mice did not learn the task at all. There was no difference in latency between the ACR14 and SAL14 mice following training with four trials per day over $7 \mathrm{~d}\left(F_{(1,13)}=\right.$ $0.65, P>0.68$; Fig. $1 G$ ) and no retention of platform location in the 4 -h probe trial on day 7 (Fig. $1 \mathrm{H}$ ), suggesting that duration of drug treatment is important.

In both ACR7 and ACR14 experiments, BrdU labeling was examined (Table 1; Fig. 1F,I-M). In the ACR7 group that was not behaviorally tested, cell proliferation ( $1 \mathrm{~d}$ after the last of seven BrdU injections, $n=6$ per group) was increased (SAL7, 11,750 \pm 512; ACR7, 13,612 $\pm 561 \mathrm{BrdU}^{+}$cells; $\left[t_{(10)}=2.24, P<0.05\right]$; Fig. 1J,K). In addition, new cell survival at $4 \mathrm{wk}$ after the last BrdU injection (SAL7, $n=7$; ACR7, $n=10$ ) was enhanced $\left(t_{(15)}=3.99\right.$, $P<0.0012$; Table 1; Fig. 1L,M). Furthermore, the percentage of double-labeled BrdU/NeuN cells was higher $\left(t_{(15)}=2.69, P<\right.$ 0.018; Fig. 1N,O). ACR14, however, had no neurogenic effect $\left(t_{(13)}=1.36, P>0.19 ;\right.$ SAL14, $n=8$; ACR14, $\left.n=7\right)$, correlating with the absence of spatial memory enhancement (Table 1; Fig. 1I).

Memory function was also enhanced following administration of the PPAR $\delta$ agonist, GW501516 $(5 \mathrm{mg} / \mathrm{kg} /$ day for $7 \mathrm{~d}$, vehicle, $n=10 ; \mathrm{GW}, n=8$ ). Two weeks after the last injection mice were trained to find a hidden platform in the Morris water maze (Morris et al. 1982) over $8 \mathrm{~d}$, with four trials per day. ANOVA with repeated measures (Days) revealed a significant interaction for latency $\left(F_{(7,16)}=2.65, P<0.02\right)$, albeit no main effect $\left(F_{(1,16)}=0.12, P>0.73\right.$; Fig. $\left.2 \mathrm{~A}\right)$. The probe trial $4 \mathrm{~h}$ after the last training trial on day 8 showed that only compoundtreated mice spent significantly more time in the platform quadrant than in all of the other quadrants $(P<0.024$; Fig. 2B), whereas the vehicle group did not show a preference. At $48 \mathrm{~h}$ after training, a trend toward a preference for the target quadrant was observed in GW-treated mice (Fig. 2C). Motor behavior and body weight $\left(F_{(1,16)}=0.73, P>0.41\right)$ were not altered. In the open-field distance traveled over $30 \mathrm{~min}$ (vehicle, $3260 \pm$ $208.1 \mathrm{~cm}$; GW, $\left.2625 \pm 298.15 \mathrm{~cm} ; F_{(1,16)}=2.87, P>0.11\right)$ and 
A
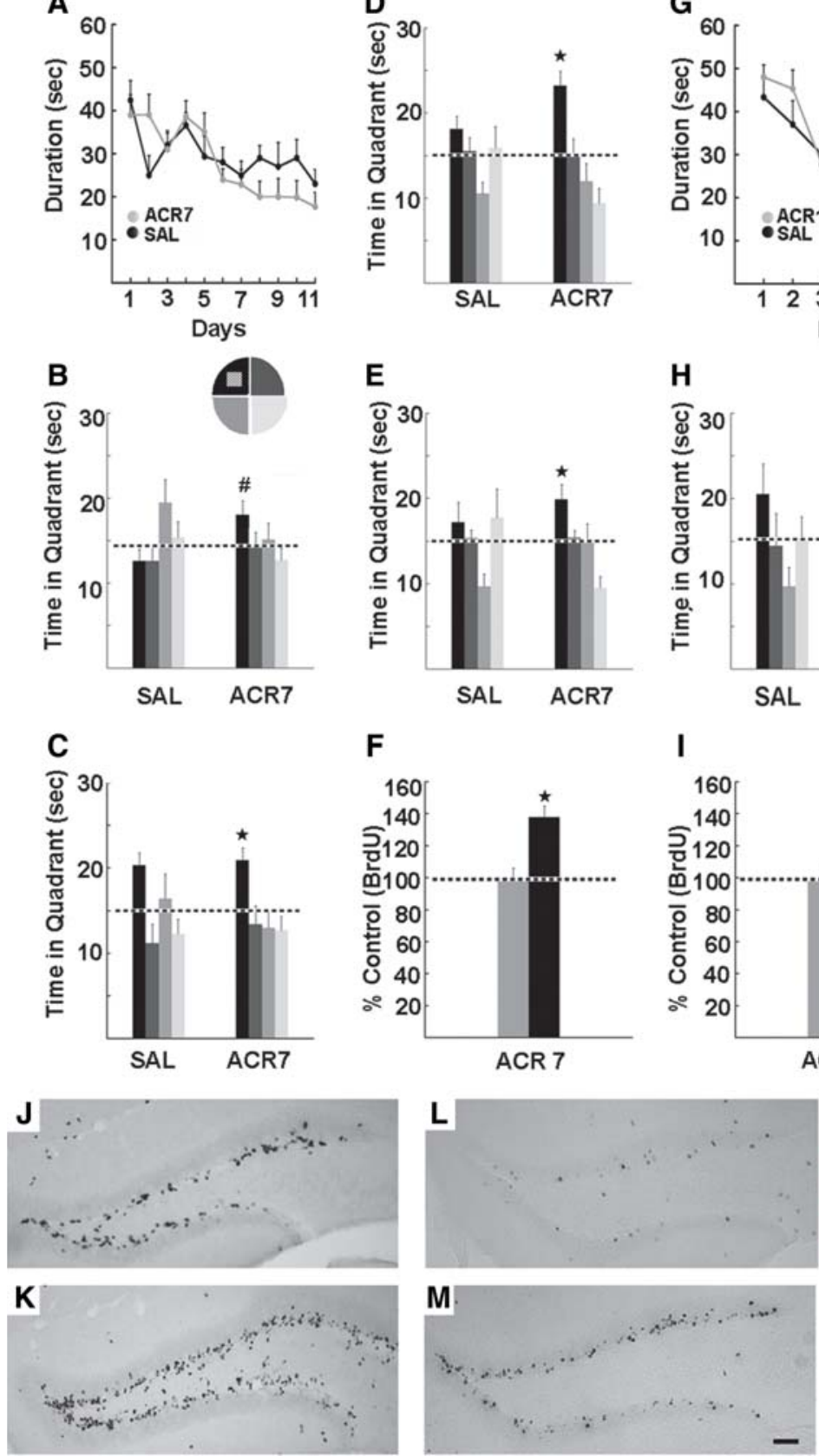

$\mathbf{F}$
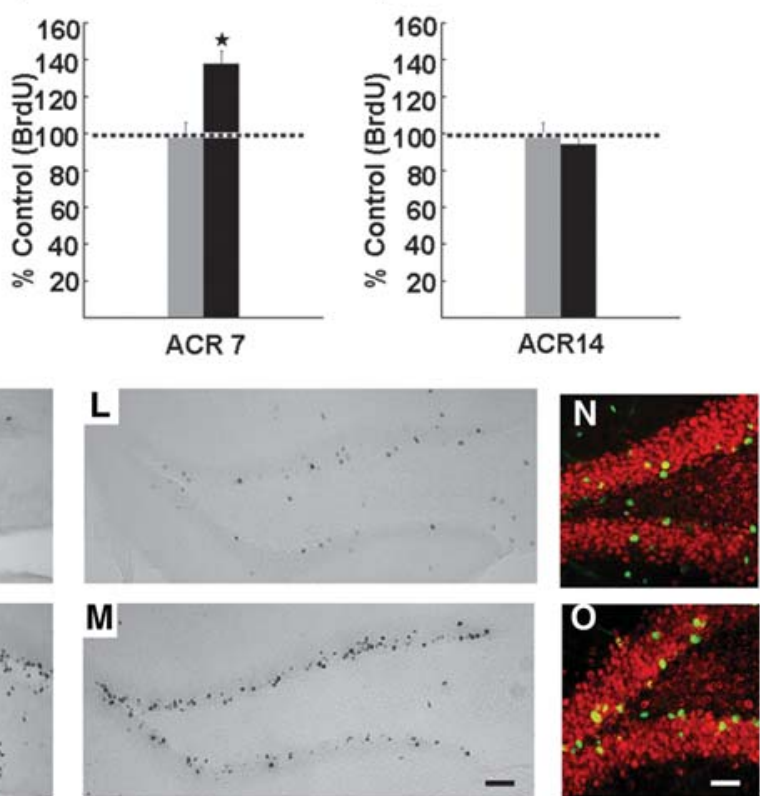

Figure 1. Water maze performance and neurogenesis in mice treated with saline $(S A L)$ or AICAR, $(500 \mathrm{mg} / \mathrm{kg}$ ) for 7 (ACR7) or $14 \mathrm{~d}$ (ACR14). (A) ACR7 mice were trained for $11 \mathrm{~d}$ with two trials per day in the Morris water maze, 2 wk after injections. Latency to the platform did not differ between the groups. $(B, C)$ However, the ACR7 mice performed better than SAL7 mice in probe trials performed $4 \mathrm{~h}$ after the last training session on days 8 and 11 . (B) In the day 8 probe ACR7 mice showed a significant preference for the target area as compared with SAL7 mice $\left({ }^{P} P<0.05\right)$. (C) In the day 11 probe only the ACR7 mice preferred the platform quadrant in comparison to the other quadrants ${ }^{*} P<$ $0.02)$. $(D, E)$ Upon training to a new platform location with four trials per day over $5 \mathrm{~d}$, significant retention of platform location was observed $(D) 4 \mathrm{~h}\left({ }^{*} P<0.006\right)$ and $(E) 24 \mathrm{~h}\left({ }^{*} P<0.04\right)$ after the last training session in ACR7 mice. $(G, H)$ Longer treatment with AICAR over $14 \mathrm{~d}$ had no effect on water-maze performance. ACR14 mice were trained with four trials per day for $7 \mathrm{~d}$. $(G)$ There was no difference in acquisition between the groups. $(H)$ ACR14 mice showed no retention of spatial memory in the 4-h probe trial. (I) In addition, there was no effect of $\mathrm{ACR} 14$ on $\mathrm{BrdU}^{+}$cell number, whereas $(F)$ ACR7 significantly enhanced new cell survival. $(J-O)$ Photomicrographs of BrdU ${ }^{+}$cells $1 \mathrm{~d}(J, K)$ and $4 \mathrm{wk}$ $(L, M)$ after the last of a daily series of seven $\operatorname{BrdU}(50 \mathrm{mg} / \mathrm{kg})$ and AICAR $(500 \mathrm{mg} / \mathrm{kg})$ injections in SAL7 $(J, L)$ and ACR7 mice $(K, M)$. Scale bar, $50 \mu \mathrm{m}$. $(N, O)$ Confocal images of BrdU-positive cells in SAL7 $(N)$ and ACR7 mice $(O) 4$ wk after the last injection. Sections were immunofluorescent doublelabeled for BrdU (green) and NeuN, indicating neuronal phenotype (red). Scale bar, $20 \mu \mathrm{m}$. Error bars, SEM. average latency on the accelerating rotarod to the first fall (vehicle, $176.51 \pm 20.85 \mathrm{sec} ; \mathrm{GW}, 177.28 \pm 19.5$ sec; $\left.F_{(1,16)}=0.76, P>0.39\right)$ did not differ between the groups. To assess hippocampal cell genesis, double-cortin (DCX) and BrdU labeling were examined. A marginal increase in DCX labeling was observed (vehicle, $2180 \pm 102 \mathrm{DCX}^{+}$ cells; GW, $2690 \pm 208 \mathrm{DCX}^{+}$cells; $\left[t_{(8)}=2.20, P=0.06\right]$; Fig. 2D-F). Furthermore, trends were observed in GW-treated mice toward increased BrdUpositive cell survival $\left(t_{(15)}=1.82, P=\right.$ $0.08)$ and differentiation $\left(t_{(15)}=1.89\right.$, $P=0.07$; Table 1; Fig. 2D,G,H).

In the present study we show that the PPAR $\delta$ agonist GW501516, and more profoundly so, the AMPK activator AICAR, enhance neurogenesis and spatial memory function in sedentary mice. GW enhanced retention of spatial memory, but to a lesser extent than AICAR, concurrent with a marginal increase in dentate gyrus neurogenesis. In previous work, GW treatment did not increase running endurance unless it was paired with training (Narkar et al. 2008). Our GW results appear to reflect its modest "exercise" phenotype. The AMPK agonist AICAR had more robust effects on spatial memory function, cell proliferation, and neurogenesis, consistent with its endurance phenotype. AMPK is activated by running in rodents (Winder and Hardie 1996; Steinberg and Kemp 2009) and humans (Wojtaszewski et al. 2000), and may interact with additional transcriptional regulators such as PGC1 $\alpha$ (Bronner et al. 2004; Jäger et al. 2007) to mediate endurance (Narkar et al. 2008). However, while the effects of both compounds were similar to voluntary exercise, overall, the results are more modest than those observed with running. Running improves learning and memory, and causes a two to fourfold increase in dentate gyrus neurogenesis (van Praag 2008). It remains to be determined whether combined administration of GW and AICAR would result in further cognitive and neurogenic improvements.

In initial research, demonstrating effects on exercise stamina compound administration was $4 \mathrm{wk}$, at the same dose as used here (Narkar et al. 2008), which activates AMPK- $\alpha 2$ receptors in muscle (Pold et al. 2005). However, $10 \mathrm{~d}$ of AICAR treatment mimicked the effect of $10 \mathrm{~d}$ of training on skeletal muscle AMPK activation (McConell et al. 2008). In addition, $6 \mathrm{~d}$ of GW501516 or AICAR treatment significantly changed muscle metabolic gene expression (Narkar et al. 2008). In our study, the PPAR $\delta$ agonist 


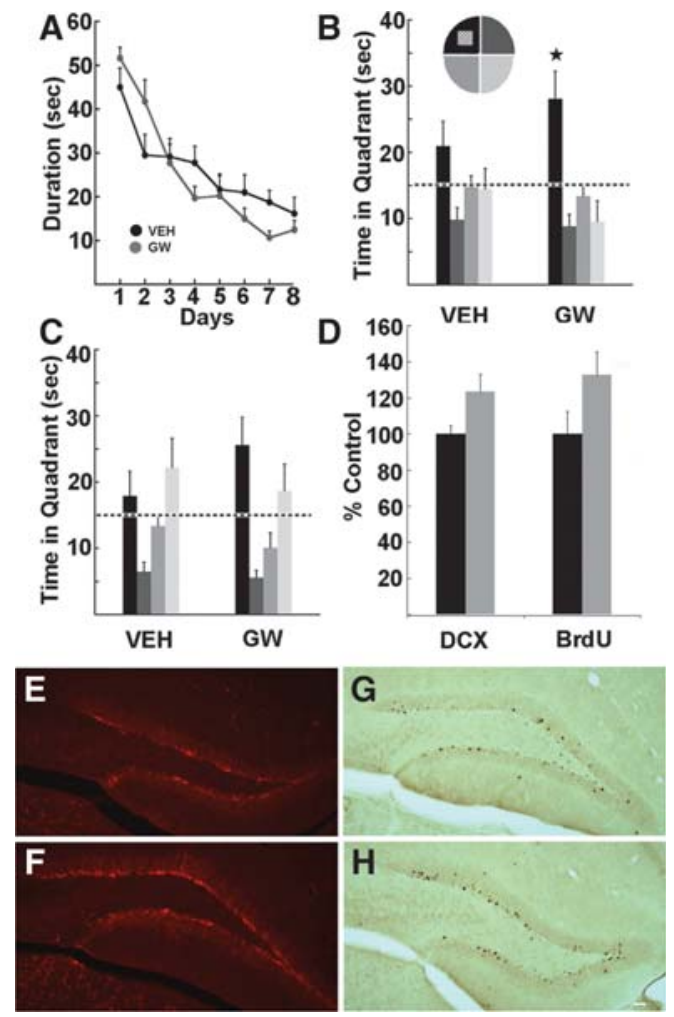

Figure 2. The PPAR $\delta$ agonist $\mathrm{GW}$ enhances Morris water-maze performance and new cell genesis. Mice were treated with vehicle (VEH) or GW $(5 \mathrm{mg} / \mathrm{kg})$ for $7 \mathrm{~d}$. Two weeks after treatment, mice were trained for $8 \mathrm{~d}$ with four trials per day to find the hidden platform. (A) A significant interaction for latency over days was observed between the groups $(P<$ 0.02 ). Probe trials were carried out $4 \mathrm{~h}(B)$ and $48 \mathrm{~h}(C)$ after the last training trial. (B) At $4 \mathrm{~h}$, only $\mathrm{GW}$-injected mice showed a significant preference for the target zone as compared with all other quadrants of the pool $(P<0.024)$. (C) At $48 \mathrm{~h}, \mathrm{GW}$ mice showed a trend toward a preference for the target area. $(D)$ A trend toward enhanced new cell genesis was observed in GW mice based on both $\operatorname{DCX}(P=0.06)$ and BrdU $(P=0.08)$ labeling. $(E, F)$ Images of $D C X$-positive cells in $(E)$ vehicle and (F) GW mice. $(G, H)$ Photomicrographs of BrdU-positive cells 4 wk after the last injection in $(G)$ vehicle and $(H)$ GW mice. Scale bar, $20 \mu \mathrm{m}$. Error bars, SEM.

was given at a $5 \mathrm{mg} / \mathrm{kg}$ dose for 1 wk to prevent hepatic toxicity (Tanaka et al. 2003). Furthermore, previous research using AMPK activation typically applied a brief exposure or a single dose (Higashida et al. 2008). In the present experiments, the effects of AICAR were clearly dependent on the duration of administration, as $7 \mathrm{~d}$ of treatment enhanced adult neurogenesis and performance in the water maze, but $14 \mathrm{~d}$ did not. It is likely that AMPK activation may have bidirectional effects on cognition similar to differential effects of short-term and chronic treatment in other systems (Fan et al. 2009). The difference between the 7 and $14 \mathrm{~d}$ of treatment may be explained by the recent finding that short-term AICAR treatment promoted sirtuin 1 protein expression in skeletal muscle, whereas $14 \mathrm{~d}$ of treatment did not (Suwa et al. 2010). Furthermore, exercise itself, when performed extensively, as in marathon racing and other forms of prolonged, heavy exertion, may increase susceptibility to inflammatory processes. We hypothesize that long-term injection of AICAR may have similar effects (Akerstrom and Pedersen 2007).

Previous investigations into potential cognitive effects of these compounds yielded equivocal results. A PPAR $\delta$ agonist ameliorated maze learning deficits in a mouse model of diabetes, but has not been tested in normal controls (de la Monte et al. 2006). Systemic activation of AMPK improved maze learning in calorie-restricted mice (Dagon et al. 2005), but this could be attributed to the dietary regimen (Fontán-Lozano et al. 2007). Intracerebral infusion of AICAR impaired memory function (Dash et al. 2006), and in vitro application reduced long-term potentiation in hippocampal slices (Potter et al. 2010). These mixed results may reflect the route of drug administration. Indeed, although AMPK and PPAR $\delta$ are expressed in neural cells (Hall et al. 2008; Dasgupta and Milbrandt 2009) and agonists are generally considered neuroprotective when applied in culture (Culmsee et al. 2001; Ayasolla et al. 2005; Iwashita et al. 2006; Dasgupta and Milbrandt 2007), the compounds used have a very low ability to cross the blood brain barrier, estimated at $<1 \%$ for AICAR (Marangos et al. 1990). Thus, only when administered peripherally, AICAR and GW may lead to a release of factors from muscle into circulation and so enhance hippocampal synaptic plasticity and cell genesis.

Support for the cognitive effects of the compounds comes from the modest increase in double-cortin (Brown et al. 2003) and BrdU labeling following treatment with GW, as well as from the significant increase in neurogenesis with AICAR. Indeed, enhancement of adult neurogenesis has been associated with improved learning and memory (van Praag 2008; Creer et al. 2010). It is likely that these neurogenic effects are also mediated by indirect activation of peripheral factors that can cross the blood brain barrier. However, it is of interest to note that PPARs play a role in neural stem cell proliferation, migration, and differentiation (Cimini and Cerù 2008). In addition, AMPK is considered important for brain development and the maintenance of neural stem cells (Lee et al. 2007; Dasgupta and Milbrandt 2009). Mutant mice lacking the regulatory AMPK $\beta 1$ subunit show atrophy of the dentate gyrus (Dasgupta and Milbrandt 2009). Interestingly, similar to hippocampal neurogenesis (Kuhn et al. 1996) and synaptic plasticity (Scheff and Price 2006), AMPK activity declines with aging in rat skeletal muscle (Reznick et al. 2007), raising the possibility that muscle AMPK levels may be a biomarker for hippocampal plasticity.

In conclusion, we show that muscle endurance enhancing compounds improve spatial memory in sedentary mice. The behavioral enhancement may be due at least in part to increased dentate gyrus neurogenesis (Gobeske et al. 2009; Pieper et al. 2010). These findings may lead to development of therapeutic agents that confer the benefits of exercise in disease or environmental conditions where activity is compromised.

\section{Acknowledgments}

This research was supported by the Intramural Research Program of the NIH, National Institute on Aging (NIA). We thank Donna Tignor, James Hopkins, Mike Still, and Derrick Haire for animal care and technical assistance. We thank Dr. Jaroslaw Aronowski for insightful comments on the manuscript.

\section{References}

Akerström TC, Pedersen BK. 2007. Strategies to enhance immune function for marathon runners: What can be done? Sports Med 37: 416-419.

Ayasolla KR, Singh AK, Singh I. 2005. 5-aminoimidazole-4-carboxamide-1beta-4-ribofuranoside (AICAR) attenuates the expression of LPS- and A $\beta$ peptide-induced inflammatory mediators in astroglia. $J$ Neuroinflammation 2: 21. doi: 10.1186/1742-2094-2-21.

Bronner M, Hertz R, Bar-Tana J. 2004. Kinase-independent transcriptional co-activation of peroxisome proliferator-activated receptor $\alpha$ by AMP-activated protein kinase. Biochem J 384: 295-305.

Brown JP, Couillard-Després S, Cooper-Kuhn CM, Winkler J, Aigner L, Kuhn HG. 2003. Transient expression of double-cortin during adult neurogenesis. J Comp Neurol 467: 1-10. 
Cimini A, Cerù MP. 2008. Emerging roles of peroxisome proliferator-activated receptors (PPARs) in the regulation of neural stem cells proliferation and differentiation. Stem Cell Rev 4: 293-303.

Cotman CW, Berchtold NC, Christie LA. 2007. Exercise builds brain health: Key roles of growth factor cascades and inflammation. Trends Neurosci 30: $464-472$.

Creer DJ, Romberg C, Saksida LM, van Praag H, Bussey TJ. 2010. Running enhances spatial pattern separation in mice. Proc Natl Acad Sci 107: 2367-2372.

Culmsee C, Monnig J, Kemp BE, Mattson MP. 2001. AMP-activated protein kinase is highly expressed in neurons in the developing rat brain and promotes neuronal survival following glucose deprivation. J Mol Neurosci 17: 45-58.

Dagon Y, Avraham Y, Magen I, Gertler A, Ben-Hur T, Berry EM. 2005. Nutritional status, cognition, and survival: A new role for leptin and AMP kinase. J Biol Chem 280: 42142-42148.

Dasgupta B, Milbrandt J. 2007. Resveratrol stimulates AMP kinase activity in neurons. Proc Natl Acad Sci 104: 7217-7222.

Dasgupta B, Milbrandt J. 2009. AMP-activated protein kinase phosphorylates retinoblastoma protein to control mammalian brain development. Dev Cell 16: 256-270.

Dash PK, Orsi SA, Moore AN. 2006. Spatial memory formation and memory-enhancing effect of glucose involves activation of the tuberous sclerosis complex-Mammalian target of rapamycin pathway. $J$ Neurosci 26: 8048-8056.

de la Monte SM, Tong M, Lester-Coll N, Plater M, Wands JR. 2006. Therapeutic rescue of neurodegeneration in experimental type 3 diabetes: Relevance to Alzheimer's disease. J Alzheimers Dis 10: 89-109.

Fabel K, Fabel K, Tam B, Kaufer D, Baiker A, Simmons N, Kuo CJ, Palmer TD. 2003. VEGF is necessary for exercise-induced adult hippocampal neurogenesis. Eur J Neurosci 18: 2803-2812.

Fan X, Ding Y, Brown S, Zhou L, Shaw M, Vella MC, Cheng H, McNay EC, Sherwin RS, McCrimmon RJ. 2009. Hypothalamic AMP-activated protein kinase activation with AICAR amplifies counterregulatory responses to hypoglycemia in a rodent model of type 1 diabetes. Am J Physiol Regul Integr Comp Physiol 296: 1702-1708.

Fontán-Lozano A, Sáez-Cassanelli JL, Inda MC, de los Santos-Arteaga M, Sierra-Domínguez SA, López-Lluch G, Delgado-García JM, Carrión AM. 2007. Caloric restriction increases learning consolidation and facilitates synaptic plasticity through mechanisms dependent on NR2B subunits of the NMDA receptor. J Neurosci 27: 10185-10195.

Gobeske KT, Das S, Bonaguidi MA, Weiss C, Radulovic J, Disterhoft JF, Kessler JA. 2009. BMP signaling mediates effects of exercise on hippocampal neurogenesis and cognition in mice. PLoS One 4: e7506. doi: 10.1371/journal.pone.0007506.

Gomez-Pinilla F, Vaynman S, Ying Z. 2008. Brain-derived neurotrophic factor functions as a metabotrophin to mediate the effects of exercise on cognition. Eur J Neurosci 28: 2278-2287.

Hall MG, Quignodon L, Desvergne B. 2008. Peroxisome proliferator-Activated receptor $\beta / \delta$ in the brain: Facts and hypothesis. PPAR Res 2008: 780452. doi: 10.1155/2008/780452.

Hardie DG. 2004. The AMP-activated protein kinase pathway-new players upstream and downstream. I Cell Sci 117: 5479-5487.

Higashida K, Higuchi M, Terada S. 2008. Potential role of lipin-1 in exercise-induced mitochondrial biogenesis. Biochem Biophys Res Commun 374: 587-591.

Hillman CH, Erickson KI, Kramer AF. 2008. Be smart, exercise your heart: Exercise effects on brain and cognition. Nat Rev Neurosci 9: 58-65.

Iwashita A, Muramatsu Y, Yamazaki T, Muramoto M, Kita Y, Yamazaki S, Mihara K, Moriguchi A, Matsuoka N. 2006. Neuroprotective efficacy of the peroxisome proliferator-activated receptor $\delta$-selective agonists in vitro and in vivo. J Pharmacol Exp Ther 320: 1087-1096.

Jäger S, Handschin C, St-Pierre J, Spiegelman BM. 2007. AMP-activated protein kinase (AMPK) action in skeletal muscle via direct phosphorylation of PGC-1 $\alpha$. Proc Natl Acad Sci 104: 12017-12022.

Kuhn HG, Dickinson-Anson H, Gage FH. 1996. Neurogenesis in the dentate gyrus of the adult rat: Age-related decrease of neuronal progenitor proliferation. J Neurosci 15: 2027-2033.
Lee JH, Koh H, Kim M, Kim Y, Lee SY, Karess RE, Lee SH, Shong M, Kim JM, Kim J, et al. 2007. Energy-dependent regulation of cell structure by AMP-activated protein kinase. Nature 447: 1017-1020.

Marangos PJ, Loftus T, Wiesner J, Lowe T, Rossi E, Browne CE, Gruber HE. 1990. Adenosinergic modulation of homocysteine-induced seizures in mice. Epilepsia 31: 239-246.

McConell GK, Manimmanakorn A, Lee-Young RS, Kemp BE, Linden KC, Wadley GD. 2008. Differential attenuation of AMPK activation during acute exercise following exercise training or AICAR treatment. J Appl Physiol 105: 1422-1427.

Morris RG, Garrud P, Rawlins JN, O’Keefe J. 1982. Place navigation impaired in rats with hippocampal lesions. Nature 24: 681-683.

Narkar VA, Downes M, Yu RT, Embler E, Wang YX, Banayo E, Mihaylova MM, Nelson MC, Zou Y, Juguilon H, et al. 2008. AMPK and PPAR $\delta$ agonists are exercise mimetics. Cell 134: 405-415.

Pieper AA, Xie S, Capota E, Estill SJ, Zhong J, Long JM, Becker GL, Huntington P, Goldman SE, Shen CH, et al. 2010. Discovery of a proneurogenic, neuroprotective chemical. Cell 142: 39-51.

Pold R, Jensen LS, Jessen N, Buhl ES, Schmitz O, Flyvbjerg A, Fujii N, Goodyear LJ, Gotfredsen CF, Brand CL, et al. 2005. Long-term AICAR administration and exercise prevents diabetes in ZDF rats. Diabetes 54: 928-934.

Potter WB, O'Riordan KJ, Barnett D, Osting SM, Wagoner M, Burger C, Roopra A. 2010. Metabolic regulation of neuronal plasticity by the energy sensor AMPK. PLoS One 5: 8996. doi: 10.1371/ journal.pone.0008996.

Reznick RM, Zong H, Li J, Morino K, Moore IK, Yu HJ, Liu ZX, Dong J, Mustard KJ, Hawley SA, et al. 2007. Aging-associated reductions in AMP-activated protein kinase activity and mitochondrial biogenesis. Cell Metab 5: 151-156.

Scheff SW, Price DA. 2006. Alzheimer's disease-related alterations in synaptic density: Neocortex and hippocampus. J Alzheimers Dis 9: $101-115$.

Steinberg GR, Kemp BE. 2009. AMPK in Health and Disease. Physiol Rev 89: 1025-1078.

Suwa M, Nakano H, Radak Z, Kumagai S. 2010. Short-term adenosine monophosphate-activated protein kinase activator 5-aminoimidazole-4-carboxamide-1- $\beta$-d-ribofuranoside treatment increases the sirtuin 1 protein expression in skeletal muscle. Metabolism. doi: 10.1016/j.metabol.2010.03.003.

Tanaka T, Yamamoto J, Iwasaki S, Asaba H, Hamura H, Ikeda Y, Watanabe M, Magoori K, Ioka RX, Tachibana K, et al. 2003. Activation of peroxisome proliferator-activated receptor $\delta$ induces fatty acid $\beta$-oxidation in skeletal muscle and attenuates metabolic syndrome. Proc Natl Acad Sci 100: 15924-15929.

Trejo JL, Carro E, Torres-Aleman I. 2001. Circulating insulin-like growth factor I mediates exercise-induced increases in the number of new neurons in the adult hippocampus. J Neurosci 21: $1628-1634$.

van Praag H. 2008. Neurogenesis and exercise: Past and future directions. Neuromolecular Med 10: 128-140.

van Praag H, Christie BR, Sejnowski TJ, Gage FH. 1999. Running enhances neurogenesis, learning, and long-term potentiation in mice. Proc Natl Acad Sci 96: 13427-13431.

Wang YX, Zhang CL, Yu RT, Cho HK, Nelson MC, Bayuga-Ocampo CR, Ham J, Kang H, Evans RM. 2004. Regulation of muscle fiber type and running endurance by PPARס. PLoS Biol 2: e294. doi: 10.1371/ journal.pbio.0020294

Winder WW, Hardie DG. 1996. Inactivation of acetyl-CoA carboxylase and activation of AMP-activated protein kinase in muscle during exercise. Am J Physiol Endocrinol Metab 270: E299-E304.

Wojtaszewski JF, Nielsen P, Hansen BF, Richter EA, Kiens BJ. 2000. Isoform-specific and exercise intensity-dependent activation of 5 -AMP-activated protein kinase in human skeletal muscle. J Physiol 528: $221-226$.

Received September 3, 2010; accepted in revised form October 20, 2010. 


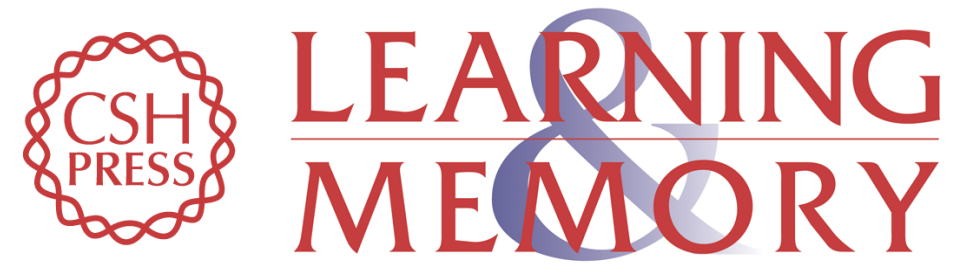

\section{Endurance factors improve hippocampal neurogenesis and spatial memory in mice}

Tali Kobilo, Chunyan Yuan and Henriette van Praag

Learn. Mem. 2011, 18:

Access the most recent version at doi:10.1101//m.2001611

References This article cites 43 articles, 11 of which can be accessed free at:

http://learnmem.cshlp.org/content/18/2/103.full.html\#ref-list-1

License

Email Alerting Receive free email alerts when new articles cite this article - sign up in the box at the Service top right corner of the article or click here. 